\title{
DISASTERS AND EPIDEMICS
}

Colonel J. G. P. POWER, M.B., B.Ch., D.P.H., D.I.H., D.T.M.\&H., L/R.A.M.C. Army School of Health, Ash Vale*

SUMMARY: Prevention and control of epidemic disease in a disaster situation is a priority task. Field hygiene units are trained in disease control in war. This paper describes the planning, organisation, training and deployment of Field Hygiene Platoons (T.\&A.V.R.) and Field Hygiene sections in disaster control in peace.

\section{Introduction}

The effects of natural calamities in human populations are similar to those caused by major wars. Whereas the latter occur less frequently today, severe earthquakes, floods, hurricanes and other cataclysmic events are reported almost every week in the mass media. Factors such as population growth, urbanisation and economic specialisation in many countries result nowadays in disasters which are becoming increasingly disruptive and expensive.

The problems of military aid to the civilian community in this country are fairly well understood and provision for help is covered by Government circulars in the form of Defence Council Instructions, No. 76 of 1969, No. 147 of 1970, and others. The situation is not so clear in other countries where the major disasters occur. However, in recent years various international bodies have taken a more direct interest in disaster control. Efforts are now directed towards stimulating national governments to deal more effectively with disasters, assisted by international agencies as necessary.

Disasters can be classified into two separate groups, natural and man-made, but there may be some overlap. For instance, the 800 or so earthquakes in Denver, Colorado, which occurred between 1962 and 1966 may have been connected with the injection of contaminated waste into a 12,000 foot-deep well drilled for this purpose. The commonest disasters are:-

Natural disasters. Earthquakes, serious floods, forest fires and gale force winds (tornadoes, typhoons and hurricanes).

Man-made disasters. Explosions, railway accidents, air crashes and pollution incidents (air) (smog), nuclear (Windscale), gas spillages and oil leaks (Torrey Canyon).

\section{Planning for natioual disasters}

Planning for national disasters is now becoming quite sophisticated and this paper outlines the general approach and some detailed specific problems of disease prevention.

\section{Historical surveys}

In ancient times natural calamities were considered as "Acts of God (or the Gods)". Hence the word disaster means an " unfavourable aspect of a star or planet ", or even an "obnoxious planet". Individuals could do little but pray for deliverance or accept inevitable death or serious injury. In latter days current research into history 


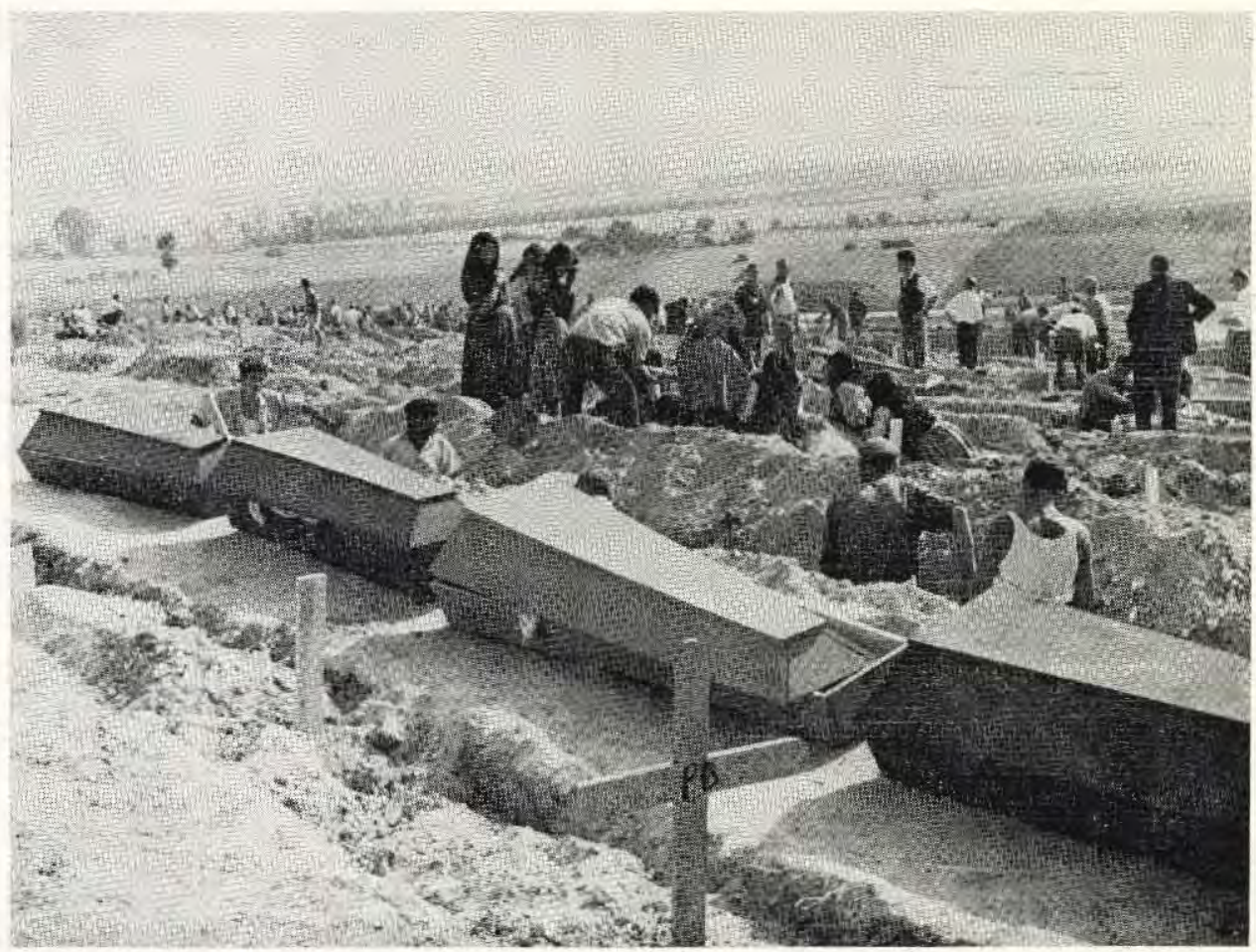

Skopje, Yugoslavia. The dead awaiting burial

has shown that locations and periodicity of earthquakes and floods can be forecast to some extent. This means that it is possible to avert disasters sometimes, or at least mitigate their worse effects. Japan which has had many devastating earthquakes in the past has reduced its total casualty list in earthquakes to 305 over the past 25 years.

\section{International co-operation}

W.H.O., U.N.E.S.C.O., N.A.T.O. and other international bodies have initiated research and development into disaster control in recent years. N.A.T.O. set up a "Committee on the Challenges of Modern Society" (1969) in Brussels which adopted the following 8 projects: Road safety. Disaster control. Air pollution. Open water pollution. Inland water pollution. Motivation problems in modern industrial society. Transmission of scientific knowledge in decision making. Environment and the strategy of territorial development.

The United States of America and Italy co-pilot in the Disaster Control project. The aims are to exchange information with member countries on recent scientific advances in disaster control, to assist those nations in developing preventive techniques and to set up central pools of manpower, equipment, food, clothing and medicines to provide direct assistance as necessary.

The Society of Occupational Medicine held a Symposium in London also on “Planning for National Disasters" (1969) which concentrated thought on man-made 
disasters. However, three factors common to all types of disaster were identified as being vital to successful planning, namely:

Training and Rehearsal for what might be expected when a disaster actually occurs.

Communications to be established rapidly and effectively between the disaster site and all relief services in the area.

Control Personinel to be clearly identified and their duties defined at the disaster site.

The Lancet (1971) points out the need for a centrally controlled permanent disasterrelief flying squad in the United Kingdom.

\section{Priority tasks}

In health and medical planning the following priority tasks must be considered: 1. Burial of the dead, 2. Disposal of refugees, 3. Emergency treatment and casualty evacuation and 4. Prevention and control of epidemic disease.

The main purpose of this paper is to outline the training requirements for Field hygiene units directed to the fourth priority task of disease control. In effect, comprehensive planning will also involve hygiene control of certain aspects of priorities 1 , 2 and 3.

\section{Epidemic disease control}

Communicable disease is still the major concern of more than half the world's population and a great deal of it stems, like cholera, from a lack of understanding and poor environmental and hygienic standards. The Director-General of the World Health Organisation (1970) states, in his annual report, that if the world's population continues to increase, and if there is further pollution and the basic requirements of life fail to reach a minimum standard, then the world's health can improve only if these problems are confronted and solved. It is against this background that the vital importance of epidemic disease control in disaster situations is stressed in training programmes at the Army School of Health.

Special courses are arranged for T. \&A.V.R. General and Field Hospitals, Field Hygiene Sections/Platoons, civilian Police Field Hygiene personnel, Army Catering Corps cooks, and others, as required. Medical officer courses are also covered. The training is fully integrated with the Field Training Wing and other departments under the overall supervision of the Training and Development Wing of the R.A.M.C. Training Centre. A Symposium on Disaster Control includes the setting of hypothetical, but realistic, epidemic disease situations for solution by syndicated groups of students. This is especially relevant to unit and individual training of Field Hygiene Sections/ Platoons, Army Health Inspectors and Hygiene Assistants. An outline plan of this form of training covers the following aspects:

\section{A Symposium of Disaster Control}

\section{Prevision}

The historical survey. Allocation of available national resources. Internation assistance required. Training and rehearsal of Field hygiene units and individual hygiene personnel. 


\section{Provision}

Survey of the disaster area. The overall plan of action. Detailed provision of resources in terms of men, equipment and transport.

\section{Prevention-Epidemic disease control}

Direct action: Water purification. Food control. Field sanitation. Specific disease control.

Indirect action: Safe disposal of human and animal dead. Hygiene of accommodation, feeding and general control of large groups of refugees. Assistance to Field hygiene units and others in hygiene procedures.

\section{A cholera control programme}

World wide spread of cholera in recent years and especially the major disasters in East Pakistan clearly pinpoint the importance of including this disease in the training of hygiene and other personnel. Maximum use is made of teaching aids at the Army School of Health and in particular the outside model ground with its many and varied sanitary appliances. Groups of students are syndicated as in each separate Field Hygiene Section or Platoon and a cholera problem would be set as a major task, but there would be at least three or four separate other health hazards to be dealt with also. The syndicates are expected to set up control programmes and an element of competition is introduced as a stimulus. Solutions to the problems are seldom clear cut and are usually varied but within narrow limits. This is achieved by basing teaching on the 'five link chain' as shown by Skinner (1970). This represents communicable disease as stemming from a source, the responsible organism being discharged or extracted via an appropriate exit portal, transmitted by a variety of routes to a target and achieving entry to the latter by a suitable portal of entry. Successful control depends on removal or severance of one or more links in this chain of disease transmission. This system ensures that syndicates will deploy their resources to the best effect. Those experienced and well trained units seldom deviate in correct disposition of their men, equipment and transport, but the real crux of the matter is the correct allocation of priorities. Using the 'five link chain' model for cholera (Fig. 1) it is possible to establish a system of priorities which might vary, but within fairly narrow limits only, related to local and general factors in each separate disaster situation.
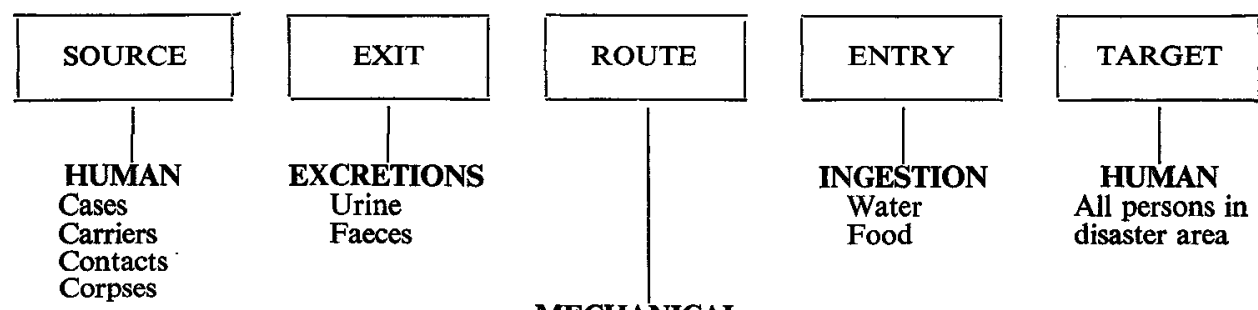

MECHANICAL

disaster area

Contaminated Water/Food

Direct Contact, as hands, contaminated surfaces

\section{BIOLOGICAL}

Vector Houseflies

Fig. 1. The chain of infection in cholera 
Using Fig. 1, and from experience of such situations in practice, control measures would be implemented in the following priorities:

Route: 1. Purification of drinking water. 2. Prevention of food contamination. 3. Adequate sanitary disposal of excreta. 4. Housefly control measures. 5. Cleansing and disinfection of living accommodation.

Target: 6. Personal hygiene, such as hand washing. 7. Cholera vaccination programme.

Source: 8. Isolation of cases and treatment of cholera. 9. Carrier/contact tracing plus isolation or surveillance and treatment.

From this it is clear that Hygiene personnel are responsible for the priorities outlined for the "Route" and to some extent for the "Target". Similarly Hospital personnel would be largely responsible for the "Source" assisted by Hygiene personnel as necessary. It is in the integration of these responsibilities within a co-ordinated, properly directed programme, that the true art and science of epidemic disease control lies.

The duties of Field hygiene personnel include the ability to organise and direct available labour into these vital tasks. Health education on a very basic level must also be applied in the personal hygiene field as hand washing. Techniques of cooking and preventing food contamination and of adequate waste disposal must be taught. Adequate disposal of human excreta must also be taught. The first problem is to adapt the physical environment to provide people with the means to limit cholera spread. The second and by far the most difficult aspect is to educate and to assist people in the best use of these facilities. Assar (1971) has produced a splendid booklet under World Health Organisation aegis on this whole subject. It is encouraging to note that many of his illustrations are taken from the Manual of Army Health (1965).

\section{Conclusion}

Recent experience of personnel who have been in disaster situations are valuable in training programmes, for example, Field Hygiene Sections in British Honduras (1962) and Jordan (1970), the author in the Agadir, Morocco earthquake (1960). Participation of units and individuals in future natural or man-made disasters should be considered. With the development of W.H.O., N.A.T.O. and other International Disaster Relief Organisations this might be possible in future. The basic training in Disaster Control now provided to T. \& A.V.R. and regular Army personnel will ensure that they are ready and willing to perform a first class job if given a chance to have a "crack at the real thing."

\section{REFERENCES}

Assar, M. (1971), Guide to Sanitation in Natural Disasters. W.H.O. Geneva.

Inaugural Meeting of the Committee on the Challenges of Modern Society (1969). N.A.T.O. letter XVIII/2, 15 to 18 Feb. N.A.T.O. Information Service.

LANCET (1971). 6th Leader Article. Lancet i, 175.

Skinner, H. G. (1970). Proc. roy. Soc. Med. 63, 523.

Symposium (1969). Planning for National Disasters. Trans. Soc. Occup. Med. 20, 17 W.H.O. (1970). Annual Report of the Director-General to the World Health Assembly and to the United Nations. W.H.O. Geneva. 